\title{
Semeadura com Pouco Revolvimento de Solo como Auxílio no Manejo de Plantas Daninhas em Milho
}

\author{
Low-Disturbance Sowing: a Weed Management Tool in Corn \\ THEISEN, G. ${ }^{2}$ e BIANCHI, M.A. ${ }^{3}$
}

\begin{abstract}
RESUMO - Foi desenvolvido um equipamento, denominado ERRS, que, acoplado aos discos de corte das semeadoras de plantio direto, reduz o revolvimento de solo no momento da semeadura dos cultivos. Para avaliar a capacidade de essa ferramenta auxiliar o manejo de plantas daninhas, dois experimentos foram conduzidos em Cruz Alta-RS, nos quais se determinou a exposição de solo em linhas de semeadura de milho, a densidade e local de emergência de plantas daninhas e a interação dessas características com o controle químico da flora infestante. Utilizou-se o delineamento de blocos casualizados, com parcelas subdivididas e cinco repetições, sendo avaliados, em cada experimento, os fatores: controle químico, incluindo-se testemunha não tratada; e ERRS. O protótipo em avaliação reduziu a exposição do solo nas linhas de semeadura em até $78 \%$, proporcionando redução na emergência de plantas daninhas, como Bidens sp. (55\%), Brachiaria plantaginea (até 37\%), Ipomoea sp. (50\%) e Raphanus raphanistrum (26\%). As espécies Bidens sp., B. plantaginea e $R$. raphanistrum germinaram predominantemente nas linhas de semeadura do milho; para as demais plantas daninhas avaliadas essa tendência não foi tão evidente, principalmente Cardiospermum halicacabum e Euphorbia heterophylla. O uso do ERRS na semeadora de plantio direto diminuiu a exposição do solo nas linhas de semeadura do milho, reduziu a densidade de plantas daninhas e otimizou o controle químico de parte da flora infestante.
\end{abstract}

Palavras-chave: herbicidas, manejo cultural, plantio direto, semeadora.

\begin{abstract}
A sowing tool denominated ERRS was developed, which, when coupled to the straw-cutting disks of no-till planters, reduces soil disturbance during crop sowing. To evaluate the effect of this tool on weed management, two experiments were carried-out at Cruz Alta-RS, Brazil. Soil exposure at corn row sowing, weed emergence density and site (row and inter-row) and the interaction of these characteristics with chemical weed control were determined. Both experiments were conducted in a split-plot design with five repetitions to test the factors weed control and tool used. The prototype evaluated kept the soil mulch almost intact when planting corn, with soil exposure in the field being reduced up to $78 \%$, with consequent reduction in emergence of Bidens sp. (55\%), Brachiaria plantaginea (up to 37\%), Ipomoea sp. (50\%) and Raphanus raphanistrum (26\%). The species Bidens $s p$., B. plantaginea and $\boldsymbol{R}$. raphanistrum germinated predominantly in the plant rows. This tendency was not so evident in the other weeds studied, mainly $\mathbf{C}$. halicacabum and $\boldsymbol{E}$. heterophylla. The use of the proposed equipment decreased soil exposure in the corn sowing rows, reducing the density of several weeds and improving the chemical weed control of the crop.
\end{abstract}

Keywords: herbicides, cultural control, no-till, seeder

Recebido para publicação em 10.5.2009 e na forma revisada em 12.3.2010

2 Engo-Agro-, M.Sc., pesquisador da Embrapa Clima Temperado, BR 392, km 78, Caixa Postal 403, 96001-970 Pelotas-RS, <giovani@cpact.embrapa.br>; ${ }^{3}$ Engo-Agro${ }^{-}$, D.Sc., pesquisador da Fundacep/Fecotrigo, Caixa Postal 10, $98100-970$ Cruz Alta-RS, $<$ mariobianchi@fundacep.com.br>.

Planta Daninha, Viçosa-MG, v. 28, n. 1, p. 93-102, 2010 


\section{INTRODUÇÃO}

O cultivo dos solos no sistema de plantio direto está presente na maior parte das lavouras anuais do Sul do Brasil. Nas demais regiões brasileiras, essa modalidade de cultivo vem sendo gradativamente adaptada (Bolliger et al., 2006; Oliveira, 2003) e tem demonstrado substituir convenientemente o sistema convencional de produção agrícola (Vuaden 2003; Landers, 2004; Bernoux, 2006; Carneiro, 2009). Embora nas áreas conduzidas sob sistemas conservacionistas existam fatores que reduzem a ocorrência de plantas daninhas, como a manutenção da palha sobre o solo e a rotação de culturas (Trezzi \& Vidal, 2004; Anderson, 2008), diversas espécies se adaptam a esse ambiente e às medidas predominantes utilizadas para seu controle. A integração de métodos diretos de controle com formas de supressão pode representar o modo mais adequado para o manejo das plantas daninhas (Upadhyay, 2006; Sanyal et al., 2008), especialmente em culturas anuais, como a soja (Theisen et al., 2000; Correia et al., 2005) e o milho (Balbinot Jr. et al., 2007).

Desenvolveu-se e avaliou-se um equipamento adaptável às semeadoras de plantio direto, que reduz a exposição de solo no momento da semeadura dos cultivos. Concebida para atender à necessidade de aprimorar os sistemas conservacionistas quanto à erosão nos sulcos de semeadura e à cobertura plena de sementes dos cultivos pelo solo (Baker, 2003; Casão Junior et al., 2006), identificouse, nessa ferramenta, elevado potencial para a supressão de plantas daninhas. As características do equipamento podem ser traduzidas, ainda, na possibilidade de efetuar semeaduras mesmo sob camadas abundantes de cobertura vegetal, em reduzir a aderência de solo aos discos das semeadoras, na uniformidade da emergência e da população das culturas e na menor exposição do solo à ação do sol e das chuvas.

Os herbicidas do grupo das s-triazinas são largamente utilizados no Brasil, sobretudo nas culturas de milho, cana-de-açúcar, entre outras. Suas principais características são o controle de plantas daninhas dicotiledôneas, a aplicação predominante em pré-emergência e o efeito residual (Roman et al., 2007). Após a aplicação, esses herbicidas podem ficar sorvidos na matéria orgânica (Shelton et al., 1998; Hang et al., 2007), têm a degradação microbiana como um mecanismo importante de dissipação no solo (Queiroz \& Monteiro, 2000) e apresentam alto potencial de lixiviação (Correia \& Langenbach, 2006). Por essas características, esses herbicidas poderiam, em tese, perder sua eficiência no plantio direto, uma vez que são aplicados sobre a palha e ocorre, geralmente, alto teor de matéria orgânica na camada mais superficial do solo. Contudo, as s-triazinas são empregadas em grande parte das lavouras de milho, tanto em áreas de plantio convencional quanto no plantio direto. Possivelmente, o efeito supressor da cobertura morta sobre as plantas daninhas, associado à manutenção dos herbicidas adsorvidos na matéria orgânica próximo da superficie do solo, onde se concentra a maior parte do banco de sementes das plantas daninhas em plantio direto, podem compensar eventuais fatores restritivos à eficiência deles nessa situação (Almeida, 1988; Fornarolli et al., 1998; Theisen, 1998; Oliveira et al., 2001).

A exposição de sementes à luz e a variações de temperatura, umidade e oxigenação promove a germinação em diversas espécies daninhas (Baskin \& Baskin, 1989; Fleck et al., 2001; Aarestrup et al., 2008); nesse aspecto, práticas culturais que interfiram minimamente no status de dormência dos bancos de sementes podem contribuir para reduzir o impacto das plantas daninhas nos cultivos (Theisen, 1998; Kurstjens, 2007; Vivian et al., 2008). Nesse sentido, a execução deste trabalho teve o objetivo de avaliar a integração da semeadura com mínimo distúrbio do solo à ação de herbicidas no manejo de plantas daninhas na cultura do milho em plantio direto.

\section{MATERIAL E MÉTODOS}

Dois experimentos foram realizados no município de Cruz Alta, RS, em área cultivada no sistema de plantio direto, em Latossolo Vermelho-Escuro com $55 \%$ de argila. A cobertura vegetal na semeadura era de $3,2 \mathrm{t} \mathrm{ha}^{-1}$ de massa seca, composta por resíduos culturais de aveia-preta e de nabo forrageiro, 
dessecados com glifosato a $1.080 \mathrm{~g} \mathrm{ha}^{-1}$, aos sete dias antes da semeadura do milho. O primeiro experimento foi implantado em 15/ 10 , sob condições adequadas de umidade e de friabilidade do solo; o segundo, em 26/10, três dias após a ocorrência de precipitação pluvial de $35 \mathrm{~mm}$, foi caracterizado por maior aderência de solo aos discos de corte da semeadora. Utilizou-se milho híbrido triplo com espaçamento de $75 \mathrm{~cm}$ entre linhas, na densidade de 54.000 sementes ha ${ }^{-1}$, cujos tratos culturais e de manejo seguiram as indicações técnicas adequadas. A semeadora era composta por discos frontais de corte, discos distribuidores de sementes e fertilizantes e sistema de cobertura dos sulcos (modelo Semeato SHM 11/13 com cinco linhas de cultivo). A essa semeadora foi feita a adaptação de estruturas compostas por lâminas metálicas, posicionadas em ambos os lados de cada disco de corte de palha; as principais ações deste protótipo [denominado ERRS ("equipamento redutor do revolvimento do solo")] são auxiliar o corte da palha, minimizar o revolvimento de solo no momento da semeadura dos cultivos e manter os discos de corte com o minimo de solo aderido.

Em cada experimento, o milho foi semeado em faixas de cinco linhas, alternando-se o uso do ERRS (com e sem), sendo os tratamentos aplicados em parcelas de $7 \mathrm{~m}$ de comprimento. Os herbicidas pré-emergentes foram aplicados imediatamente após a semeadura, e os pósemergentes, entre 20 e 25 dias após a emergência, com aspersor costal pressurizado com $\mathrm{CO}_{2}$, utilizando-se volume de calda de $130 \mathrm{~L} \mathrm{ha}^{-1}$, obtido com pressão de $160 \mathrm{kPa}$, velocidade de $1 \mathrm{~m} \mathrm{~s}^{-1}$ e seis pontas de pulverização do tipo XR 110.015, espaçadas de $0,5 \mathrm{~m}$. Os herbicidas, doses e épocas de aplicação utilizados em cada experimento estão descritos nas Tabelas 2 (experimento 1) e 3 (experimento 2).

O delineamento experimental utilizado foi de blocos casualizados, com parcelas subdivididas. Nas parcelas principais alocou-se a modalidade de semeadura (com e sem ERRS) e, nas subparcelas, os tratamentos herbicidas, incluindo-se testemunhas não tratadas. As parcelas mediram $7,0 \times 3,75 \mathrm{~m}$, considerandose como área útil os $6 \mathrm{~m}$ das linhas centrais de semeadura.
Para avaliar a exposição do solo causada pela semeadora, analisaram-se imagens obtidas com máquina fotográfica digital posicionada no centro das parcelas e na altura de $1,90 \mathrm{~m}$, abrangendo uma área de $2,7 \mathrm{~m}^{2}$. As imagens (1.280 x 960 pixels) foram analisadas no software Sigma Scan, no qual se ajustou um algoritmo para separação de cores e cálculo de áreas. A proporção de solo exposto em relação à área coberta com palha foi então normatizada em escala percentual e, assim, analisada estatisticamente.

As características de densidade e de localização das plantas daninhas foram avaliadas no estádio V2 da cultura, antes da aplicação dos herbicidas pós-emergentes, com a contagem de plântulas em áreas delimitadas de $25 \times 25 \mathrm{~cm}$, posicionadas no centro das parcelas, sobre as três linhas centrais e nas entrelinhas de semeadura do milho, num total de seis amostras por parcela. No primeiro experimento a flora infestante foi composta por Brachiaria plantaginea, Bidens sp., Cardiospermum halicacabum, Digitaria horizontalis e Euphorbia heterophylla, enquanto no segundo experimento as infestantes eram B. plantaginea, D. horizontalis, Ipomoea sp. e Raphanus raphanistrum.

O efeito do equipamento e de sua interação com a ação dos herbicidas foi determinado: a) pela densidade de plantas daninhas no início do desenvolvimento do milho, comparando-se parcelas tratadas com herbicidas pré-emergentes com todas as demais não tratadas; b) pela cobertura do solo proporcionada por B. plantaginea (espécie predominante no primeiro experimento) aos 25 dias após a aplicação dos herbicidas pós-emergentes; e c) pelo nível de controle de $R$. raphanistrum (no segundo experimento), aos 8 e 24 dias após a aplicação dos herbicidas pós-emergentes. No final do ciclo da cultura, avaliou-se a produtividade de grãos, padronizada para a umidade de $13 \%$.

Os dados foram analisados quanto à normalidade e homocedasticidade, transformados quando necessário e submetidos à análise de variância pelo teste $\mathrm{F}$, nos sistemas proc univariate normal e proc glm (SAS, 1999); nos casos de significância ( $F>0,05)$, os tratamentos foram comparados utilizando-se testes de Duncan e LS-means. Variáveis populacionais 
com tratamentos desbalanceados foram analisadas com o proc mixed no software SAS (Schammass et al., 2005) e apresentadas em forma gráfica (Browne, 1979; Perri \& Iemma, 1999).

\section{RESULTADOS E DISCUSSÃO}

\section{Efeito de ERRS na exposição do solo nas linhas de semeadura}

O resultado da operação de semeadura é a criação de um sulco, que poderá ter maior ou menor evidência em função da umidade do solo, do tipo de semeadora, da cobertura do solo e da velocidade da operação (Reis et al., 2004). A exposição de solo gerada na semeadura de milho no primeiro experimento, implantado quando o solo se encontrava em condição adequada de umidade, foi relativamente baixa, variando entre 1,9 (com ERRS) e 8,8\% (sem ERRS). No segundo trabalho, implantado três dias após precipitação pluvial de $35 \mathrm{~mm}$, o solo aderia-se mais intensamente aos discos e estruturas do equipamento, os sulcos de semeadura eram mais evidentes e a proporção de solo exposto em relação à área total variou entre 6,5 (com ERRS) e 17,9\% (sem ERRS). Em ambas as situações, o equipamento foi eficiente em reduzir a exposição de solo na semeadura, diminuindo essa característica em $78 \%$ no primeiro experimento e em $63 \%$ no segundo (Tabela 1).

\section{Densidade e localização das plantas daninhas}

O efeito do ERRS na densidade e na localização espacial das plantas daninhas foi acentuado para $R$. raphanistrum, Bidens sp. e $B$. plantaginea, espécies que apresentaram maior população nas linhas de semeadura, comparativamente às entrelinhas (Figura 1). Em solo não protegido pela palha os estímulos necessários à superação da dormência de sementes de diversas plantas daninhas podem ser intensos (Cousens \& Mortimer, 1995), e essa, provavelmente, seja a razão da predominância dessas invasoras nas linhas de semeadura, especialmente naquelas com mais solo exposto. Para C. halicacabum e E. heterophylla não se observou o mesmo padrão de localização; possivelmente, esse comportamento se origina no modo predominante de superação da dormência de suas sementes quanto à exigência luminosa e resposta às variações de microclima (Souza, 1995; Salvador et al., 2007). A semeadura com pouco revolvimento de solo reduziu a população de Ipomoea sp. em até $50 \%$ (Figura 1i); contudo, a variabilidade dos dados não permitiu distinguir o local predominante de germinação dessa planta daninha: se nas linhas ou nas entrelinhas de semeadura do milho. Já a distribuição irregular da emergência e de posicionamento de D. horizontalis - planta daninha comum aos dois experimentos - não permitiu identificar o seu padrão predominante de localização nas áreas cultivadas com milho (Figura $1 \mathrm{~b}, \mathrm{~g}$ ), tampouco indicou ser afetada pelo efeito do ERRS.

Encontraram-se variações no padrão de posicionamento predominante de $B$. plantaginea que permitiram identificar, ao menos em parte, a capacidade e o limite do ERRS em suprimir a emergência dessa infestante. Enquanto no primeiro experimento houve efeito acentuado do equipamento em reduzir a densidade da planta daninha nas linhas de semeadura e se verificou diferença na população entre as linhas e entrelinhas de cultivo (Figura 1a), no segundo trabalho o uso do protótipo não foi suficiente para suprimir a população nas linhas, verificou-se alta população nas entrelinhas e houve maior uniformidade de distribuição da planta daninha entre os locais avaliados (Figura 1f). Esse fato deve-se ao maior revolvimento de solo (Tabela 1), associado à elevada densidade desta espécie na área experimental. Não se descarta, contudo, que possa ter ocorrido interação desses fatores com diferenças em aspectos

Tabela 1 - Exposição do solo gerada pela semeadura de milho em plantio direto na palha, com e sem adaptação na semeadora

\begin{tabular}{|l|c|c|}
\hline \multirow{2}{*}{ Semeadora } & Experimento 1 & Experimento $2^{1^{1 /}}$ \\
\cline { 2 - 3 } & \multicolumn{2}{|c|}{ solo exposto na área cultivada (\%) } \\
\hline Adaptada & $1,9 \mathrm{a}^{2 /}$ & $6,5 \mathrm{a}$ \\
\hline Não adaptada & $8,8 \mathrm{~b}$ & $17,9 \mathrm{~b}$ \\
\hline CV (\%) & 26 & 24 \\
\hline
\end{tabular}

${ }^{1 /}$ Experimento instalado em solo úmido, três dias após precipitação de $35 \mathrm{~mm} .{ }^{2 /}$ As letras comparam as médias na respectiva coluna (teste $\mathrm{F}, \mathrm{P}=0,05$ ). 

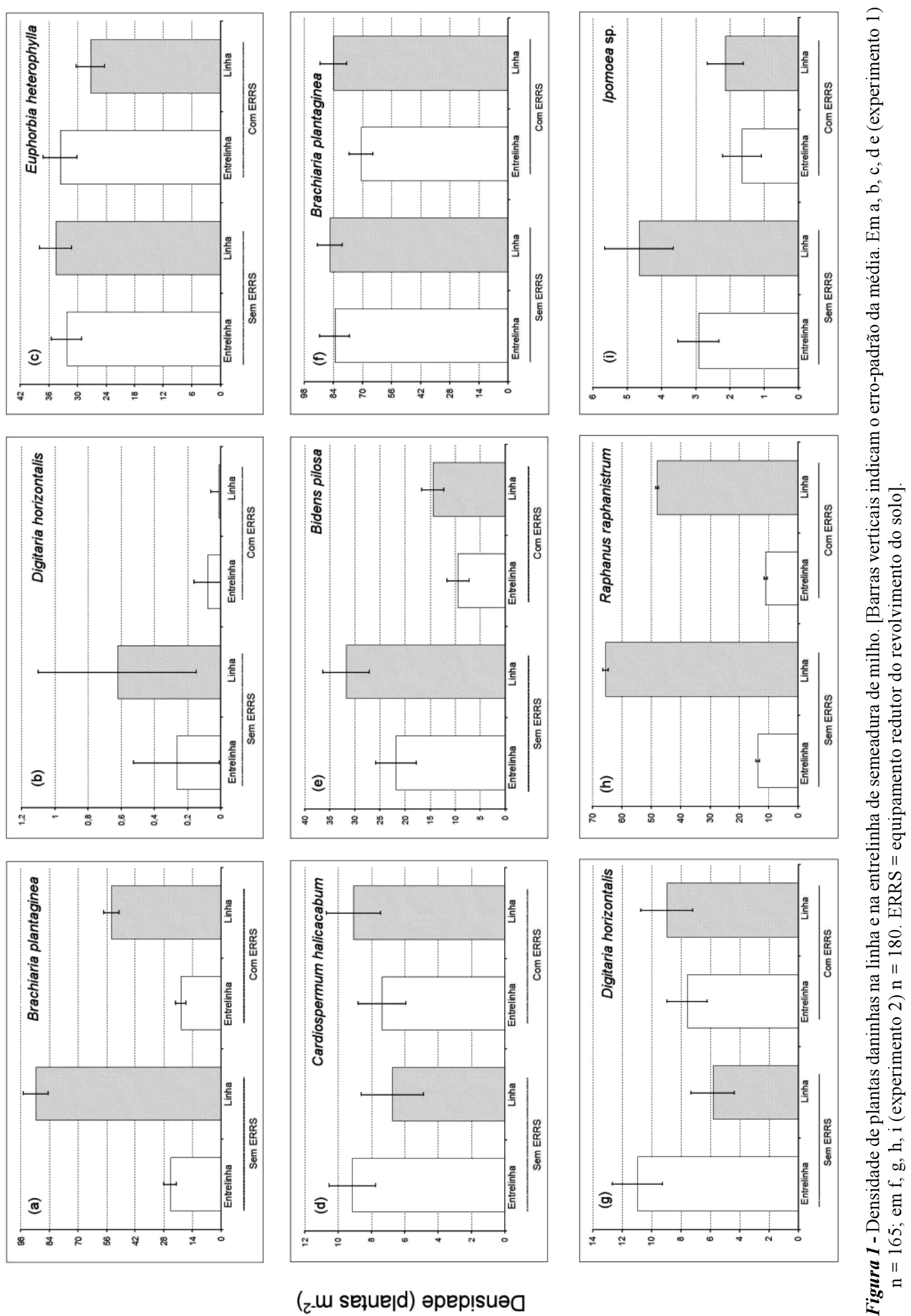

(z-u sełue|d) әреp!suə0 
fisiológicos, como superação da dormência de sementes, e climáticos, como a precipitação e temperatura, uma vez que os experimentos foram instalados em momentos distintos. Observou-se, ainda, que a população de B. plantaginea localizada nas entrelinhas do milho semeado com maior revolvimento de solo originou-se, principalmente, na germinação das sementes em torrões de solo lançados às entrelinhas no momento da semeadura e, em menor intensidade, através da palha dessecada.

Interação entre a exposição do solo na semeadura e a eficiência de herbicidas préemergentes

Ao se avaliar a população de plantas daninhas no início do desenvolvimento do milho (V2), contrastando-se o efeito do conjunto de parcelas tratadas com herbicidas pré-emergentes com as não tratadas, no primeiro experimento (Figura 2), constatou-se que $B$. plantaginea foi pouco afetada por estes herbicidas, comparada às outras espécies avaliadas (Figura 2a). Os herbicidas préemergentes reduziram a população dessa invasora em somente 9\%. Especula-se que esse fato tenha ocorrido devido à sua elevada densidade, associada à ação limitada dos princípios ativos utilizados (atrazina e simazina) sobre essa gramínea, e à retenção de parte dos herbicidas aplicados sobre a palha (Rodrigues et al., 2000). Em contraste, verificou-se maior eficácia do grupo de herbicidas pré-emergentes sobre as plantas daninhas dicotiledôneas, reduzindo significativamente a densidade de Bidens sp. (67\%), C. halicacabum (57\%) e E. heterophylla (62\%) (Figura 2a). (a)

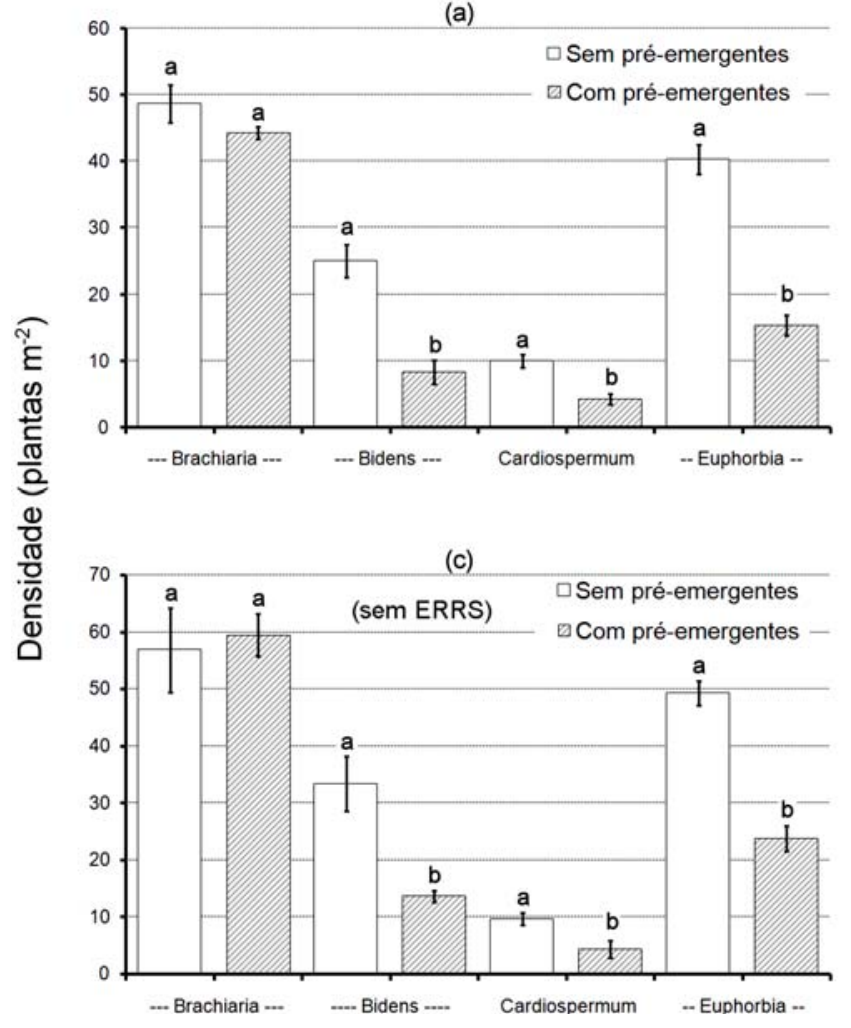

(b)

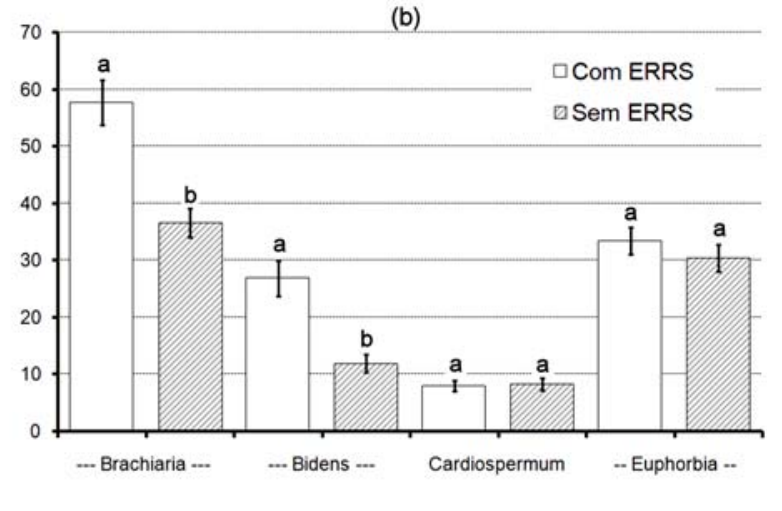

(d)

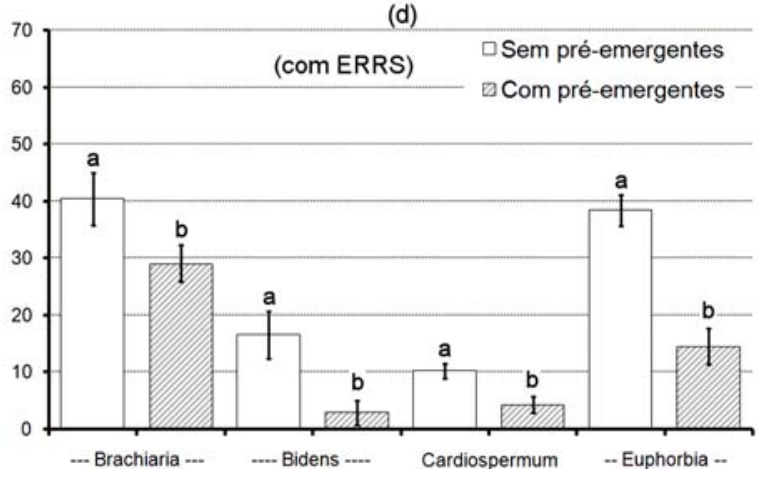

Figura 2 - Densidade de plantas daninhas em milho no estádio V2, em resposta ao efeito de herbicidas pré-emergentes (a); do ERRS (b); e da interação entre herbicidas pré-emergentes e ERRS (c, d). Barras verticais indicam o erro-padrão da média. Em (a) sem préemergentes, $n=480$; com pré-emergentes, $n=240$. Em (b), $n=360$; em (c) e (d) sem pré-emergentes, $n=240$; com préemergentes, $n=120$. ERRS = equipamento redutor do revolvimento do solo. Letras comparam a densidade por espécie, em cada gráfico (LS Means, $\mathrm{P}=0,05$ ). Dados obtidos no experimento 1 . 
Quando a população das plantas daninhas foi estudada sob o efeito do equipamento em teste (Figura 2b), verificou-se redução consistente $(\mathrm{P}<0,05)$ na população de $B$. plantaginea (37\%) e de Bidens sp. (56\%) pelo uso do ERRS na semeadora. As espécies C. halicacabum e $E$. heterophylla não diminuíram sua densidade em resposta ao equipamento (Figura $2 b$ ).

A análise da interação entre o efeito do ERRS e a ação do grupo de herbicidas pré-emergentes sobre a população de $B$. plantaginea, de Bidens sp.e de E. heterophylla (Figuras 2c, d) indicou que, ao se diminuir a população dessas plantas daninhas, ou se cultivar o solo com menor revolvimento, otimiza-se a ação de controle dos herbicidas. Somente quando o milho foi semeado com ERRS é que houve supressão de $B$. plantaginea pelo conjunto de herbicidas préemergentes, quando os produtos reduziram a densidade da invasora em 11,3 plantas $\mathrm{m}^{-2}$ (27\%). Em Bidens sp., a redução populacional proporcionada por esses herbicidas variou entre 59\% (sem ERRS) e $82 \%$ (com ERRS), representando incremento de $23 \%$ na ação de controle, enquanto sobre $E$. heterophylla, embora ERRS não tenha reduzido significativamente sua densidade, a semeadura com o equipamento otimizou os efeitos dos herbicidas pré-emergentes nessa infestante em cerca de $10 \%$. Já os níveis de controle da população de C. halicacabum pelos herbicidas pósemergentes não foram afetados pela utilização de ERRS na semeadora (Figura 2c, d).

Ao se comparar a eficácia dos tratamentos com controle químico em suprimir a ocupação do solo por B. plantaginea no estádio V8 da cultura, na semeadura sem ERRS, identificaram-se seis tratamentos em destaque dos demais, com índices de ocupação do solo pela planta daninha inferiores a $10 \%$; já ao se utilizar o ERRS no plantio, niveis inferiores a $10 \%$ de infestação foram encontrados em nove alternativas de controle químico avaliadas (Tabela 2). Observou-se ainda que atrazina + simazina (pré-e.); atrazina + simazina (pré-e.), complementados com nicosulfuron (pós-e.); e nicosulfuron+atrazina+s-metolachlor (pós-e.) tiveram incremento significativo em sua eficácia ao se promover semeadura com pouco distúrbio de solo. A ocupação do solo pela planta daninha no estádio V8 da cultura alcançou até $57,2 \%$ da superficie do terreno quando não foi empregada nenhuma medida de supressão ou de controle, e a utilização do ERRS na semeadora reduziu a presença da invasora na área em 18,5\% (Tabela 2).

O uso do ERRS na semeadora reduziu a população de Raphanus raphanistrum em 10,2 plantas $\mathrm{m}^{-2}$ (Figura $1 \mathrm{~h}$ ), o que ampliou o controle químico, na média do conjunto de tratamentos, em $17 \%$ já aos oito dias após a aplicação dos herbicidas pós-emergentes (Tabela 3). Na condição de maior população da infestante (sem ERRS), três tratamentos se destacaram dos demais: atrazina+simazina (pré-e.), mesotrione+atrazina+simazina (pós-e.) e mesotrione+atrazina+s-metolachlor (pós-e.), com níveis de controle variando entre 60 e $65 \%$. Ao se utilizar ERRS, contudo, cinco tratamentos sobressaíram no controle de $R$. raphanistrum, e elevou-se o percentual de controle desse grupo em destaque para niveis entre 70 e $85 \%$ (Tabela 3). A semeadura com pouco distúrbio do solo (com ERRS) proporcionou ganhos significativos na eficiência de controle da planta daninha para os tratamentos atrazina+s-metolachlor (pré-e.), mesotrione +atrazina (pós-e.), nicosulfuron+atrazina+smetolachlor (pós-e.) e nicosulfuron (pós-e.). Aos 24 dias após a aplicação dos herbicidas em pós-emergência, todos os tratamentos com controle químico evoluíram para uma condição de controle de $R$. raphanistrum em niveis superiores a $80 \%$.

A produtividade do milho variou na forma prevista e em conformidade com a intensidade de supressão dos tratamentos às plantas daninhas. As menores produções foram obtidas nas situações sem controle das plantas daninhas e com maior exposição de solo nas linhas da cultura (Tabelas 2 e 3 ). Sob condições adequadas de semeadura (experimento 1) não se constatou diferença significativa de produtividade entre os tratamentos com herbicida, independentemente da adaptação na semeadora (Tabela 2). Quando as condições do solo na semeadura promoveram maior revolvimento nas linhas de cultivo, ocasionando a germinação de maior número de plantas daninhas (experimento 2), o equipamento diminuiu as perdas produtivas oriundas de falhas de controle químico, uniformizando a produtividade dos diversos tratamentos avaliados (Tabela 3). Destaca-se que o efeito da 
Tabela 2 - Efeito de tratamentos herbicidas e do ERRS na infestação de Brachiaria plantaginea em milho e na produtividade de grãos da cultura

\begin{tabular}{|c|c|c|c|c|}
\hline \multirow{3}{*}{ Tratamento (dose em kg ha ${ }^{-1}$ e época de aplicação) $)^{\frac{1}{}}$} & \multicolumn{2}{|c|}{ Cobertura do solo $(\%)^{\frac{2}{2}}$} & \multicolumn{2}{|c|}{ Produtividade $\left(\mathrm{kg} \mathrm{ha}^{-1}\right)$} \\
\hline & \multicolumn{4}{|c|}{ Adaptação na semeadora } \\
\hline & sem & com & sem & com \\
\hline Não tratado & $\mathrm{A}^{\frac{3}{2}} 57,2 \mathrm{a}$ & B 38,7 a & A 2264 b & B 3142 b \\
\hline Mesotrione $0,12+$ atrazina 0,7 (pós) & A $5,4 \mathrm{c}$ & A $5,8 \mathrm{c}$ & A 5652 a & A 6250 a \\
\hline Mesotrione $0,12+$ atrazina $0,75+$ simazina 0,75 (pós) & A $7,2 \mathrm{c}$ & A 7,6 bc & A 5492 a & A 5959 a \\
\hline Mesotrione $0,12+$ atrazina $1,11+$ s-metolachlor 0,87 (pós) & A $8,6 \mathrm{c}$ & A 7,4 bc & A 5795 a & A 5755 a \\
\hline Atrazina 1,25 + simazina 1,25 (pré) & A $21,6 \mathrm{~b}$ & B $18,7 \mathrm{~b}$ & A 5616 a & A $4992 \mathrm{ab}$ \\
\hline Nicosulfuron $0,6+$ atrazina 0,7 (pós) & A $6,4 \mathrm{c}$ & A $5,8 \mathrm{c}$ & A 5524 a & A 5829 a \\
\hline Atrazina $1,0+$ simazina 1,0 (pré) e mesotrione $0,06+$ atrazina 0,7 (pós) & A $7,4 \mathrm{c}$ & A $4,6 \mathrm{c}$ & A 5732 a & A 6208 a \\
\hline Atrazina $1,0+$ simazina 1,0 (pré) e mesotrione $0,12+$ atrazina 0,7 (pós) & A $7,8 \mathrm{c}$ & A $5,2 \mathrm{c}$ & A 5096 a & B 5952 a \\
\hline Atrazina 1,0 + simazina 1,0 (pré) e nicosulfuron 0,48 (pós) & A $10,0 \mathrm{bc}$ & B $6,2 \mathrm{c}$ & A 5447 a & A $5004 \mathrm{ab}$ \\
\hline Nicosulfuron $0,1+$ Atrazina $1,11+$ s-metolachlor 0,87 (pós) & A 13,2 bc & B 8,0 bc & A 5189 a & A $4681 \mathrm{ab}$ \\
\hline Nicosulfuron $0,1+$ Atrazina $0,75+$ simazina 0,75 (pós) & A 10,6 bc & A $8,0 \mathrm{bc}$ & A 6095 a & A $5851 \mathrm{a}$ \\
\hline Nicosulfuron 0,4 (pós) & A $20,0 \mathrm{~b}$ & A $17,6 \mathrm{~b}$ & A 4116 a & B $5080 \mathrm{ab}$ \\
\hline Média & 14,2 & 11,1 & 5168 & 5392 \\
\hline CV (\%) & \multicolumn{2}{|c|}{30} & \multicolumn{2}{|c|}{10} \\
\hline
\end{tabular}

$1 /$ Primeiro experimento. ${ }^{2 /}$ Percentual da superfície do solo ocupada por plantas vigorosas de B.plantaginea, no estádio V8 da cultura do milho. ${ }^{3 /}$ Letras maiúsculas comparam médias nas linhas dentro de cada variável (LSMeans; $\mathrm{P}=0,05$ ); letras minúsculas comparam médias nas colunas (Duncan, $\mathrm{P}=0,05$ )

Tabela 3 - Efeito de tratamentos herbicidas e do ERRS no controle de Raphanus raphanistrum aos oito dias após a aplicação de herbicidas pós-emergentes em milho e produtividade de grãos da cultura

\begin{tabular}{|c|c|c|c|c|}
\hline \multirow{3}{*}{ Tratamento (dose em kg ha ${ }^{-1}$ e época de aplicação) $)^{1 /}$} & \multicolumn{2}{|c|}{ Controle $(\%)$} & \multicolumn{2}{|c|}{ Produtividade $\left(\mathrm{kg} \mathrm{ha}^{-1}\right)$} \\
\hline & \multicolumn{4}{|c|}{ Adaptação na semeadora } \\
\hline & sem & com & sem & com \\
\hline Não tratado & - & - & A $1571 \mathrm{c}$ & B 2998 b \\
\hline Atrazina 1,25 + simazina 1,25 (pré) & $\stackrel{2 /}{A} 65 \mathrm{a}$ & A 70 a & A 3058 abc & A $3877 \mathrm{ab}$ \\
\hline Atrazina $1,48+$ s-metolachlor 1,16 (pré) & A $30 \mathrm{bc}$ & B 82 a & A $2437 \mathrm{bc}$ & B $3850 \mathrm{ab}$ \\
\hline Mesotrione $0,12+$ atrazina 1,23 (pós) & A $55 \mathrm{~b}$ & B 85 a & A $2545 \mathrm{bc}$ & B $4577 \mathrm{ab}$ \\
\hline Mesotrione $0,12+$ atrazina $0,75+$ simazina 0,75 (pós) & A 61 a & A $63 \mathrm{ab}$ & A 3358 abc & B $4799 \mathrm{ab}$ \\
\hline Mesotrione 0,12 + atrazina 1,11 + s-metolachlor 0,87 (pós) & A 60 a & A 76 a & A $4663 \mathrm{ab}$ & A $4751 \mathrm{ab}$ \\
\hline Nicosulfuron $0,2+$ atrazina 1,23 (pós) & A $53 \mathrm{~b}$ & A $60 \mathrm{ab}$ & A $4630 \mathrm{ab}$ & A 5722 a \\
\hline Nicosulfuron $0,2+$ atrazina $0,75+$ simazina 0,75 (pós) & A $55 \mathrm{~b}$ & A 54 b & A 5423 a & A $5183 \mathrm{ab}$ \\
\hline Nicosulfuron $0,2+$ atrazina $1,11+$ s-metolachlor 0,87 (pós) & A 46 b & B 70 a & A 5747 a & A 5552 a \\
\hline Nicosulfuron 0,4 (pós) & A $29 \mathrm{c}$ & B $48 \mathrm{~b}$ & A $4175 \mathrm{ab}$ & A $5084 \mathrm{ab}$ \\
\hline Média & 45 & 62 & 3761 & 4639 \\
\hline $\mathrm{CV}(\%)$ & \multicolumn{2}{|c|}{16} & \multicolumn{2}{|c|}{16} \\
\hline
\end{tabular}

1/ Segundo experimento. ${ }^{2 /}$ Letras maiúsculas comparam as médias das linhas dentro de cada variável (LSMeans; $\mathrm{P}=0,05$ ); letras minúsculas comparam médias nas colunas (Duncan, $\mathrm{P}=0,05$ ). 
utilização do ERRS na semeadora reduziu as perdas produtivas associadas às plantas daninhas nas parcelas testemunhas sem controle químico em $28 \%$ (experimento 1) e em $48 \%$ (experimento 2).

O equipamento proposto, quando acoplado à semeadora de plantio direto, reduziu a exposição de solo gerado na semeadura de milho e a população de algumas plantas daninhas na cultura. Bidens sp., Brachiaria plantaginea e Raphanus raphanistrum apresentaram maior germinação nas linhas de semeadura, e não se observou o mesmo comportamento em Cardiospermum halicacabum e Euphorbia heterophylla. Os herbicidas pré-emergentes, baseados em atrazina + simazina, foram eficientes em controlar Bidens sp., Cardiospermum halicacabum e Euphorbia heterophylla e aumentaram sua ação quando houve menor população de plantas daninhas devido à pouca exposição de solo nas linhas de semeadura do milho. De modo semelhante, a redução na população de $B$. plantaginea e de $R$. raphanistrum proporcionada pela semeadura com menor revolvimento do solo facilitou a ação de controle por parte dos herbicidas avaliados neste trabalho.

\section{AGRADECIMENTOS}

Ao engenheiro-agrônomo Marcelino Colla (UNITEC, Três de Maio, RS); ao técnico agrícola Adriano Luís Boss; aos produtores rurais Bruno Arns (Cruz Alta, RS) e Max Dockhorn (Três Passos, RS); à Fundacep (Cruz Alta, RS); e à Syngenta/ConsHerb, pelo apoio técnico na execução dos experimentos.

\section{LITERATURA CITADA}

AARESTRUP, J. R. et al. Análise da viabilidade de sementes de Euphorbia heterophylla. Planta Daninha, v. 26, n. 3, p. 515-519, 2008.

ALMEIDA, F. S. A alelopatia e as plantas. Londrina: IAPAR, 1988. 60 p. (IAPAR. Circular, 53).

ANDERSON, R. L. Diversity and no-till: keys for pestmanagement in the U.S. Great Plains. Weed Sci., v. 56, n. 1, p. 141-145, 2008.

BAKER, C. J. Strategies for minimum soil disturbance in no-tillage. In: WORLD CONGRESS ON CONSERVATION AGRICULTURE, 2., 2003, Foz do Iguaçu. Extended Summary... Foz do Iguaçu, 2003. p. 77-80.
BALBINOT Jr., A. A.; MORAES, A.; BACKES, R. L. Efeito de coberturas de inverno e sua época de manejo sobre a infestação de plantas daninhas na cultura de milho.

Planta Daninha, v. 25, n. 3, p. 473-480, 2007.

BASKIN, J. M.; BASKIN, C. C. Physiology of dormancy and germination in relation to seed bank ecology. In: LECK, M. A.; PARKER, V. T.; SIMPSON, R. L. (Eds.). Ecology of soil seed banks. New York: Academic Press, 1989. p. 53-66.

BERNOUX, M. et al. Cropping systems, carbon sequestration and erosion in Brazil, a review. Agron. Sustainable Develop., v. 26, p. 1-8, 2006.

BOLLIGER, A. et al. Taking Stock of the Brazilian "Zero-Till Revolution": A review of Landmark Research and Farmers's Practice. Adv. Agron., v. 91, p. 47-110, 2006.

BROWNE, R. H. On visual assessment of the significance of a mean difference. Biometrics, v. 35, n. 3, p. 657-665, 1979.

CARNEIRO, M. A. C. et al. Atributos físicos, químicos e biológicos de solo de cerrado sob diferentes sistemas de uso e manejo. R. Bras. Ci. Solo, v. 33, n. 1, p. 147-157, 2009

CASÃO JUNIOR, R. et al. (Orgs.). Sistema plantio direto com qualidade. Londrina/Foz do Iguaçu: Instituto Agronômico do Paraná - ITAIPU Binacional, 2006. v. 1. $212 \mathrm{p}$.

CORREIA, F. V.; LANGENBACH, T. Dinâmica da distribuição e degradação de atrazina em Argissolo VermelhoAmarelo sob condições de clima tropical úmido. R. Bras. Ci. Solo, v. 30, n. 1, p. 183-192, 2006.

CORREIA, N. M.; SOUZA, I. F.; KLINK, U. P. Palha de sorgo associada ao herbicida imazamox no controle de plantas daninhas na cultura da soja em sucessão. Planta Daninha, v. 23, n. 3, p. $483-489,2005$

COUSENS, R.; MORTIMER, M. Dynamics of weed populations. Cambridge: Cambridge University Press, 1995. $332 \mathrm{p}$.

FLECK, N. G. et al. Efeitos de fontes nitrogenadas e de luz na germinação de sementes de Bidens pilosa e Sida rhombifolia. Ci. Agrotec., v. 25, n. 3, p. 592-600, 2001.

FORNAROLLI, D. A. et al. Influência da cobertura morta no comportamento do herbicida atrazine. Planta Daninha, v. 16, n. 2, p. 97-107, 1998.

HANG, S.; HOUOT, B.; BARRIUSO, E. Mineralization of ${ }^{14} \mathrm{C}$-atrazine in an entic haplustoll as affected by selected winter weed control strategies. Soil Tillage Res., v. 96, n. 1-2, p. 234-242, 2007.

KURSTJENS, D. A. G. Precise tillage systems for enhanced non-chemical weed management. Soil Tillage Res., v. 97, n. 2, p. 293-305, 2007.

Planta Daninha, Viçosa-MG, v. 28, n. 1, p. 93-102, 2010 
LANDERS, J. N. Zero tillage challenges and solutions in Brazil. In: WORLD SOYBEAN RESEARCH CONFERENCE, 7.; INTERNATIONAL SOYBEAN PROCESSING AND UTILIZATION CONFERENCE, 4.; CONGRESSO MUNDIAL DE SOJA, 3., Proceedings... Londrina: Embrapa Soja, 2004. p. 274-281.

OLIVEIRA, G. B. Nonô Pereira: 25 anos plantando na palha. Passo Fundo: Aldeia Norte, 2003. 170 p.

OLIVEIRA, M. F. et al. Efeito da palha e da mistura atrazine e metolachlor no controle de plantas daninhas na cultura do milho, em sistema de plantio direto. Pesq. Agropec. Bras., v. 36, n. 1 , p. $37-41,2001$.

PERRI, S. H. V. I.; IEMMA, A. F. Procedimento "MIXED" do SAS ${ }^{\circledR}$ para análise de modelos mistos. Sci. Agric., v. 56, n. 4, p. 969-967, 1999.

QUEIROZ, B. P. V.; MONTEIRO, R. T. R. Degradação de ${ }^{14} \mathrm{C}$-atrazina sob condições semicontroladas. Pesq. Agropec. Bras., v. 35, n. 4, p. 849-856, 2000

REIS, E. F. et al. Avaliação de mecanismos rompedores e compactadores em semeadura direta. Eng. Agric., v. 12, n. 3, p. 212-221, 2004.

RODRIGUES, B. N.; LIMA, J.; YADA, I. F. U. Retenção pela palhada, de herbicidas aplicados em pré-emergência na cultura do milho, em plantio direto. R. Bras. Herbic., v. 1, n. 2 , p. $123-128,2000$.

ROMAN, E. S. et al. Como funcionam os herbicidas: da biologia à aplicação. Passo Fundo: Berthier, 2007. $158 \mathrm{p}$

SALVADOR, F. L. et al. Efeito da luz e da quebra de dormência na germinação de sementes de espécies de plantas daninhas. Planta Daninha, v. 25, n. 2, p. 303-308, 2007.

SANYAL, D. et al. Revisiting the perspective and progress of integrated weed management. Weed Sci., v. 56, n. 1, p. 161-167, 2008.

SAS Institute Inc. SAS procedure guide, Version 8. Cary: 1999.
SCHAMMASS, E. A. et al. Análise de experimento desbalanceado em parcelas subdivididas pelos procedimentos GLM e Mixed do sistema SAS. In: REUNIÃO ANUAL DA

REGIÃO BRASILEIRA DA SOCIEDADE

INTERNACIONAL DE BIOMETRIA (RBRAS), 1.; SIMPÓSIO DE ESTATÍSTICA APLICADA À EXPERIMENTAÇÃO AGRONÔMICA (SEAGRO), 11., 2005, Londrina. Anais... Londrina: 2005.

SHELTON, D. R.; SADEGHI, A. M.; ISENSEE, A. R. Effect of tillage on atrazine bioavailability. Soil Sci., v. 163, n. 111, p. 891-896, 1998.

SOUZA, R. O. Balãozinho (Cardiospermum halicacabum L.) na cultura da soja (Glycine max (L.) Merril): aspectos biológicos e controle químico. 1995. 82 f. Dissertação (Mestrado em Agronomia) - Universidade Federal de Santa Maria, Santa Maria, 1995.

THEISEN, G. Influência de palha de aveia preta em papuã (Brachiaria plantaginea (Link) Hitch.) e seu impacto em soja. 1998. 87 f. Dissertação (Mestrado em Fitotecnia) - Universidade Federal do Rio Grande do Sul, Porto Alegre, 1998.

THEISEN, G.; VIDAL, R. A.; FLECK, N. G. Redução da infestação de Brachiaria plantaginea em soja pela cobertura do solo com palha de aveia preta. Pesq. Agropec. Brasil., v. 35, n. 4, p. 753-756, 2000.

TREZZI, M. M;; VIDAL, R. A. Potencial de utilização de cobertura vegetal de sorgo e milheto na supressão de plantas daninhas em condição de campo: II Efeitos da cobertura morta. Planta Daninha, v. 22, n. 1, p. 1-10, 2004.

UPADHYAY, B. M. et al. Economics of integrated weed management in herbicide-resistant canola. Weed Sci., v. 54, n. 1, p. 138-147, 2006.

VIVIAN, R. et al Dormência em sementes de plantas daninhas como mecanismo de sobrevivência: breve revisão.

Planta Daninha, v. 26, n. 3, p. 695-706, 2008.

VUADEN, E. R. Plantio direto no cerrado: a experiência de Lucas do Rio Verde. In: WORLD CONGRESS ON CONSERVATION AGRICULTURE, 2., 2003, Foz do Iguaçu. Extended Summary... Foz do Iguaçu: 2003. p. 74-76. 